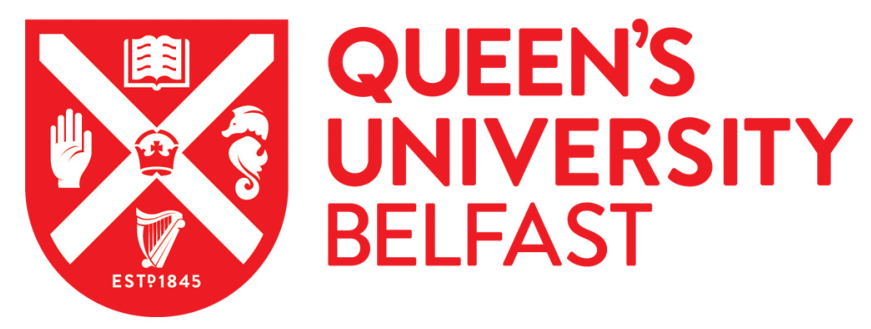

\title{
Worldwide evaluation and correction of irradiance measurements from personal weather stations under all-sky conditions
}

Lopez Lorente, J., Liu, X. A., \& Morrow, D. J. (2020). Worldwide evaluation and correction of irradiance measurements from personal weather stations under all-sky conditions. Solar Energy, 207, 925-936. https://doi.org/10.1016/j.solener.2020.06.073

\section{Published in:}

Solar Energy

\section{Document Version:}

Peer reviewed version

Queen's University Belfast - Research Portal:

Link to publication record in Queen's University Belfast Research Portal

\section{Publisher rights}

(C) 2020 Elsevier Ltd.

This manuscript is distributed under a Creative Commons Attribution-NonCommercial-NoDerivs License

(https://creativecommons.org/licenses/by-nc-nd/4.0/), which permits distribution and reproduction for non-commercial purposes, provided the author and source are cited.

\section{General rights}

Copyright for the publications made accessible via the Queen's University Belfast Research Portal is retained by the author(s) and / or other copyright owners and it is a condition of accessing these publications that users recognise and abide by the legal requirements associated with these rights.

Take down policy

The Research Portal is Queen's institutional repository that provides access to Queen's research output. Every effort has been made to ensure that content in the Research Portal does not infringe any person's rights, or applicable UK laws. If you discover content in the Research Portal that you believe breaches copyright or violates any law, please contact openaccess@qub.ac.uk. 


\title{
Worldwide evaluation and correction of irradiance measurements from personal weather stations under all-sky conditions
}

\author{
Javier López Lorente ${ }^{a *}$, Xueqin Liu ${ }^{a}$, David John Morrow ${ }^{a}$ \\ ${ }^{a}$ School of Electronics, Electrical Engineering and Computer Science \\ Queen's University Belfast, Northern Ireland, U.K. \\ *Corresponding author: jlopezlorente01(at)qub.ac.uk
}

\begin{abstract}
Personal weather stations (PWS) are gaining popularity since they provide open meteorological data with high spatial resolution. However, a number of factors may affect the quality of the measurements of these stations. PWS provide irradiance measurements using silicon-photodiode sensors, which are a low-cost and lower-maintenance option compared to thermopile-type pyranometers. Siliconphotodiode sensors present, however, several limitations related to the spectral bandwidth, the device's temperature and other affecting factors, which increase the error in the measurements. This article evaluates the accuracy of irradiance measurements from PWS under all-sky conditions. We propose a calibration method to reduce the uncertainty in the measurements based on the solar zenith angle, the temperature of the device and the clear-sky index. The proposed calibration model is evaluated in 30 personal weather stations from different producers located in 5 climate zones worldwide over several years. An average reduction of the relative mean bias error from $18.4 \%$ to $2.8 \%$ is achieved based on 5-minute instantaneous irradiance samples for clear-sky instances and it is within a $\pm 5 \%$ tolerance for all-sky conditions, where other metrics are also improved $1-4 \%$. This study helps understanding the nature of uncertainty of irradiance measurements in this increasingly used data source and provides a practical calibration method to increase accuracy of PWS data.
\end{abstract}

Keywords: solar resource, personal weather station (PWS), silicon-photodiode, pyranometer, global horizontal irradiance (GHI) 


\section{Introduction}

Solar radiation data are essential for photovoltaic and thermal solar applications in climate, energy and environmental sciences. The most accurate sources of irradiance $(G)$ data are land-based measurements obtained by well-maintained, calibrated thermopile pyranometers (Sengupta et al., 2017). Depending on the application, up to intra-minute resolution may be required. However, highquality measurements of solar irradiance with such resolution are often available for a limited number of locations due to the high cost and maintenance needs. On the other side, Personal Weather Stations (PWS) record irradiance and other meteorological data and can help increase the spatial resolution of the available data. Access to such data represents an open alternative with high-resolution data, which can complement official data sources.

A personal weather station is an outdoor weather station equipped with: (i) a thermometer, (ii) barometer, (iii) anemometer, (iv) hygrometer, and (v) wind vanes. Some more advanced models would also include a silicon-photodiode pyranometer, ultraviolet index and/or air quality sensors. PWS are owned by private individuals (e.g. weather enthusiasts) or organisations, who voluntarily donate their data. PWS data are regularly uploaded and made accessible on websites like WeatherLink, Netatmo Weathermap, Weather Underground, or EUweather. Since most of these devices report every 5 to 15 minutes, data are publicly available for free faster than other open solar radiation data sources, i.e. satellite-based or official weather stations from national meteorological services. Data from single or multiple PWS simultaneously have been extensively used in the literature for a wide range of applications and scientific fields. This is due to the diverse meteorological data produced by PWS and a growing support within the scientific community (Gharesifard et al., 2017). For example, PWS data were used in studies of hydro-meteorological phenomena, such as flashflood (Bedrina et al., 2012) or rainfall monitoring (De Vos et al., 2017). Data from PWS were used as inputs for energy modelling studies (Touzani et al., 2018; Pham et al., 2019) and for energy efficiency investigations (Kazmi et al., 2018). In the field of renewable energy and power systems, Desta et al. (2017) modelled wind production using PWS data. Bottaccioli et al. (2019) investigated solar photovoltaic power output using PWS data in the context of smart grids' management, while Inanlouganji et al. (2018) implemented solar generation forecasting using this data source. In the analysis of solar resources, López Lorente et al. (2019) showed how average hourly Global Horizontal Irradiance $(G H I)$ obtained from PWS had a higher correlation with the production of PV plants than that from official weather stations.

Despite the benefits these data have (e.g. open source and high temporal and spatial resolution), there are also several limitations, specially concerning the quality and accuracy of the measurements. In relation to irradiance observations, incorrect maintenance and lack of recalibration plans can affect the measurements of solar radiation sensors due to degradation from soiling or annual drift. Operational clock and time-stamps issues can also require extensive data processing. Consistency cannot be guaranteed in relation to external factors of the installation (e.g. orientation or shadowing) affecting their operation. In addition, PWS are often presented as plug-and-play products and field calibration is rare. PWS typically use silicon-photodiode pyranometers, which are a lower-cost option with less maintenance requirements and faster response times 
(Urraca et al., 2018). However, silicon-photodiode sensors present higher uncertainty compared to research-class, thermopile technology pyranometers due to differences in the solar response and spectrum covered. There are a number of factors influencing the response of silicon-photodiode devices, such as: (i) angle of incidence, (ii) device temperature, (iii) tilt orientation, (iv) mechanical and optical asymmetries in the instrument, (v) irradiance magnitude, and (vi) spectral response (King and Myers, 1997). The difference in $G$ readings between silicon-photodiode and thermopile pyranometers falls within $\pm 5 \%$ when devices are correctly calibrated and maintained, and the data corrected (Al-Rasheedi et al., 2018; King and Myers, 1997; Sengupta et al., 2012; Vignola et al., 2017; Walter-Shea et al., 2019). Without corrections, the differences can reach $\pm 15 \%$ (King et al., 1998).

Although Sengupta et al. (2012) concluded that uncertainties in the measurements of silicon-based devices cannot be easily quantified, empirical correction procedures have been proposed based on the absolute air mass, the solar zenith angle and the temperature of the device (King et al., 1998; King and Myers, 1997; Vignola et al., 2017; Walter-Shea et al., 2019). Such empirical models require sensor-specific data that may not be readily available for generic PWS. This is where this article makes a contribution, by proposing a correction function to estimate the broadband irradiance from the irradiance and ambient temperature reported by PWS. The contributions of this article are: (i) an evaluation of global horizontal irradiance measurements of 30 PWS located worldwide, covering 5 climatic zones according to the Köppen's classification across 8 countries. PWS data are increasingly used in research studies and evaluating the accuracy of these devices is key. To the best of our knowledge, this is the first study which undertakes a large-scale evaluation of PWS irradiance data; and (ii) a practical calibration method for the irradiance measurements of PWS. The proposed method does not require sensor-specific data, as it follows a data-driven approach and uses general metadata of the station (i.e. climate zone or producer). The article is structured as follows: section 2 presents the data sources used. Section 3 describes the methods for the analysis and the calibration method proposed. Section 4 then introduces results from both uncorrected and corrected data and the validation of the proposed calibration procedure. This is followed by a discussion in section 5. Finally, the conclusions and considerations for further work are presented in section 6 .

\section{Data Sources}

This study required extensive solar radiation data, i.e. global horizontal irradiance, from reference (thermopile) pyranometers and from personal weather stations. The reference data belong to the World Meteorological Organization's Baseline Solar Radiation Network (BSRN) and to the Measurement and Instrumentation Data Center (MIDC) by the National Renewable Energy Laboratory (NREL) of the United States' Department of Energy. The BSRN provides minutely observations of basic solar radiation variables at ground level in over 70 locations worldwide with different geographic, topographic and surface type distributions, where some stations have been reporting since 1992. The MIDC also provides 1-minute irradiance and other meteorological data from multiple stations across the United States of America. General information about the 
weather stations and periods of data accessed are presented in Table 1.

Data from PWS were obtained from Weather Underground (The Weather Company (IBM), 2019), where the selected stations provide 5-minute resolution meteorological data. Information about the selected PWS is presented in Table 2. Overall, this study considers 9 reference stations and 30 PWS, which are the closest available to those reference sites. The number of PWS considered for each reference station ranges from 1 to 6 , what depended on PWS' availability. The time range covered by the data ranges from over a month (37 days) to 8 years (3,025 days). Those stations with less than 100 days may be subject to seasonality error in their corrected form. The locations analysed extend over 5 different climatic zones according to the Köppen climate classification across 8 countries worldwide. The climates included are: (i) tropical savanna climate zone (As); (ii) dry semi-arid (steppe) climate (BSk); (iii) humid subtropical climate (Cfa); (iv) oceanic, marine west coast climate (Cfb); and (v) warm summer continental (Dfb).

Table 1: General data about the reference solar radiation stations with minutely global horizontal irradiance, including Köppen climate zone and period assessed.

\begin{tabular}{|c|c|c|c|c|c|}
\hline Site & Location & $\begin{array}{l}\text { Climate } \\
\text { Zone }\end{array}$ & $\begin{array}{c}\text { Coordinates } \\
\text { (lat, lon) }\end{array}$ & Station Network & $\begin{array}{l}\text { Period Analysed } \\
\text { (From, To) }\end{array}$ \\
\hline A & $\begin{array}{l}\text { Kailua-Kona, } \\
\text { Hawaii, USA }\end{array}$ & As & $\begin{array}{c}19.728 \\
-156.059\end{array}$ & $\begin{array}{l}\text { MIDC, NELHA; } \\
\text { Olson and Andreas (2012) }\end{array}$ & $\begin{array}{l}\text { Aug 2018, } \\
\text { Sep } 2019\end{array}$ \\
\hline B & $\begin{array}{l}\text { Boulder, } \\
\text { Colorado, USA }\end{array}$ & BSk & $\begin{array}{c}39.911 \\
-105.235\end{array}$ & $\begin{array}{l}\text { MIDC, NREL Flatirons Campus } \\
\text { (M2); Jager and Andreas (1996) }\end{array}$ & $\begin{array}{l}\text { Jul } 2011 \text {, } \\
\text { Sep } 2019\end{array}$ \\
\hline $\mathrm{C}$ & $\begin{array}{l}\text { Sarriguren, } \\
\text { Spain }\end{array}$ & $\mathrm{Cfb}$ & $\begin{array}{l}42.816 \\
-1.601\end{array}$ & $\begin{array}{l}\text { BSRN station no: } 45 \text { (CNR); } \\
\text { Olano (2019) }\end{array}$ & $\begin{array}{l}\text { Dec } 2018, \\
\text { Feb } 2019\end{array}$ \\
\hline $\mathrm{D}$ & $\begin{array}{l}\text { Fukuoka, } \\
\text { Japan }\end{array}$ & $\mathrm{Cfa}$ & $\begin{array}{l}33.582 \\
130.376\end{array}$ & $\begin{array}{l}\text { BSRN station no: } 6 \text { (FUA); } \\
\text { Dehara (2019) }\end{array}$ & $\begin{array}{l}\text { Jul } 2014 \text {, } \\
\text { Jul } 2019\end{array}$ \\
\hline $\mathrm{E}$ & $\begin{array}{l}\text { Florianopolis, } \\
\text { Brazil }\end{array}$ & $\mathrm{Cfa}$ & $\begin{array}{l}-27.605 \\
-48.523\end{array}$ & $\begin{array}{l}\text { BSRN station no: } 3 \text { (FLO); } \\
\text { Colle (2019) }\end{array}$ & $\begin{array}{l}\text { Jun } 2018 \text {, } \\
\text { Aug } 2019\end{array}$ \\
\hline $\mathrm{F}$ & $\begin{array}{l}\text { Camborne, } \\
\text { UK }\end{array}$ & $\mathrm{Cfb}$ & $\begin{array}{l}50.217 \\
-5.317\end{array}$ & $\begin{array}{l}\text { BSRN station no: } 50 \text { (CAM); } \\
\text { Hodgetts (2017) }\end{array}$ & $\begin{array}{l}\text { May } 2016 \text {, } \\
\text { Jul } 2017\end{array}$ \\
\hline G & $\begin{array}{l}\text { Cabauw, } \\
\text { Netherlands }\end{array}$ & $\mathrm{Cfb}$ & $\begin{array}{c}51.971 \\
4.927\end{array}$ & $\begin{array}{l}\text { BSRN station no: } 53 \text { (CAB); } \\
\text { Knap (2019) }\end{array}$ & $\begin{array}{l}\text { Jan } 2018 \text {, } \\
\text { Jul } 2019\end{array}$ \\
\hline $\mathrm{H}$ & $\begin{array}{l}\text { Sonnblick, } \\
\text { Austria }\end{array}$ & $\mathrm{Cfb}$ & $\begin{array}{l}47.054 \\
12.958\end{array}$ & $\begin{array}{l}\text { BSRN station no: } 75(\mathrm{SON}) \text {; } \\
\text { Olefs (2019) }\end{array}$ & $\begin{array}{l}\text { Apr 2016, } \\
\text { Aug } 2019\end{array}$ \\
\hline I & Toravere, Estonia & $\mathrm{Dfb}$ & $\begin{array}{c}58.254 \\
26.462\end{array}$ & $\begin{array}{l}\text { BSRN station no: } 9 \text { (TOR); } \\
\text { Kallis (2019) }\end{array}$ & $\begin{array}{l}\text { Jan 2016, } \\
\text { Aug } 2019\end{array}$ \\
\hline
\end{tabular}


Table 2: General data about the personal weather stations (PWS) studied including days of data available, valid data points under all-sky conditions, share of clear-sky samples over the total data points, distance to reference site, and hardware producer.

\begin{tabular}{|c|c|c|c|c|c|c|}
\hline PWS & Station ID & $\begin{array}{c}\text { Days of } \\
\text { data }\end{array}$ & $\begin{array}{c}\text { Valid } \\
\text { data points }\end{array}$ & $\begin{array}{c}\text { Clear-sky } \\
\text { samples (\%) }\end{array}$ & $\begin{array}{c}\text { Distance to } \\
\text { reference site }(\mathrm{km})\end{array}$ & $\begin{array}{l}\text { Hardware } \\
\text { producer }\end{array}$ \\
\hline A1 & KHIKAILU149 & 196 & 16,492 & 24 & 7.86 & Producer 1 \\
\hline $\mathrm{A} 2$ & KHIKAILU122 & 407 & 11,824 & 27 & 14.07 & Producer 1 \\
\hline A3 & KHIHOLUA14 & 83 & 6,909 & 12 & 14.28 & Producer 1 \\
\hline A4 & KHIHOLUA8 & 345 & 20,410 & 30 & 11.20 & Producer 1 \\
\hline B1 & KCOARVAD297 & 60 & 7,317 & 35 & 4.66 & Producer 1 \\
\hline $\mathrm{B} 2$ & KCOARVAD147 & 37 & 3,912 & 31 & 6.85 & Producer 1 \\
\hline B3 & KCOGOLDE242 & 286 & 25,254 & 20 & 7.34 & Producer 1 \\
\hline B4 & KCOARVAD291 & 138 & 16,973 & 26 & 8.15 & Producer 1 \\
\hline B5 & KCOLOUIS71 & 397 & 37,201 & 26 & 6.88 & Producer 1 \\
\hline B6 & KCOSUPER7 & 3,025 & 263,088 & 35 & 6.87 & Producer 2 \\
\hline $\mathrm{C} 1$ & INAURROZ2 & 88 & 2,968 & 14 & 12.60 & $\mathrm{~N} / \mathrm{A}$ \\
\hline D1 & IIIZUKA5 & 266 & 23,925 & 19 & 28.14 & Producer 1 \\
\hline D2 & IFUKUOKA4 & 1,832 & 156,094 & 24 & 1.23 & Producer 2 \\
\hline D3 & $\mathrm{I} 1118$ & 1,552 & 125,084 & 20 & 12.75 & Producer 2 \\
\hline E1 & IFLORIAN25 & 433 & 38,737 & 24 & 11.39 & Producer 1 \\
\hline E2 & IFLORI30 & 41 & 3,691 & 30 & 7.38 & Producer 1 \\
\hline E3 & ISCLAGOA2 & 259 & 22,571 & 22 & 6.33 & Producer 1 \\
\hline $\mathrm{F} 1$ & IREDRUTH3 & 435 & 38,386 & 11 & 7.11 & Producer 1 \\
\hline $\mathrm{F} 2$ & IGWINEAR2 & 228 & 11,531 & 6 & 5.40 & Producer 3 \\
\hline G1 & ILOPIK10 & 94 & 12,126 & 13 & 2.03 & $\mathrm{~N} / \mathrm{A}$ \\
\hline G2 & ISCHOONH5 & 538 & 50,569 & 21 & 5.36 & Producer 1 \\
\hline G3 & IBENSCHO5 & 561 & 47,938 & 16 & 5.33 & $\mathrm{~N} / \mathrm{A}$ \\
\hline G4 & IHEKENDO4 & 143 & 17,000 & 20 & 9.36 & $\mathrm{~N} / \mathrm{A}$ \\
\hline $\mathrm{H} 1$ & ISALZBUR156 & 1,244 & 97,948 & 12 & 15.19 & $\mathrm{~N} / \mathrm{A}$ \\
\hline $\mathrm{H} 2$ & IHEILI2 & 147 & 15,895 & 15 & 8.13 & Producer 1 \\
\hline H3 & IMALLNIT3 & 987 & 74,456 & 9 & 17.34 & $\mathrm{~N} / \mathrm{A}$ \\
\hline I1 & ITARTU39 & 88 & 10,153 & 17 & 21.92 & $\mathrm{~N} / \mathrm{A}$ \\
\hline $\mathrm{I} 2$ & ILOHKV1 & 128 & 15,419 & 21 & 22.98 & $\mathrm{~N} / \mathrm{A}$ \\
\hline I3 & ITARTUMA15 & 1,323 & 32,084 & 21 & 21.12 & $\mathrm{~N} / \mathrm{A}$ \\
\hline I 4 & ITARTU40 & 39 & 4,596 & 18 & 20.13 & Producer 1 \\
\hline
\end{tabular}




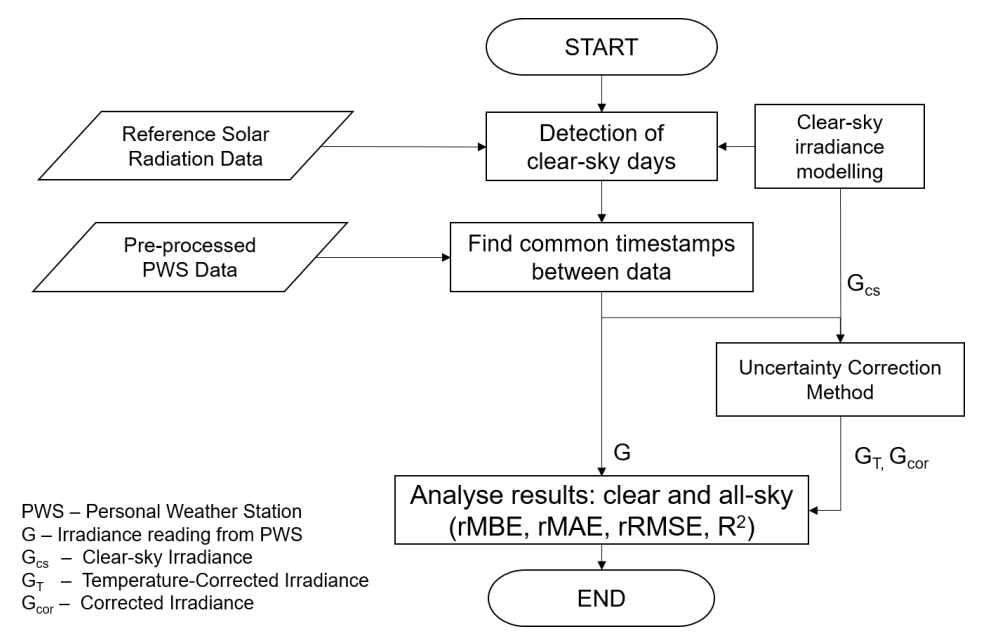

Figure 1: Flowchart of methods used in the assessment of PWS irradiance data.

\section{Methodology}

This section describes the methods used to analyse and correct the uncertainty of irradiance measurements from PWS compared to reference stations. A flowchart illustrating the methodology utilised is presented in Fig. 1. The methodology consists of five stages as follows: (i) detection of clear-sky periods; (ii) modelling of clear-sky irradiance; (iii) pre-processing of PWS data; (iv) correction of the uncertainty of PWS measurements; and (v) evaluation of the results.

\subsection{Detection of clear-sky periods}

Solar resource varies in time and space. As the PWS and the reference sites are not in the same locations, this affects solar resource comparisons due to, for example, local cloud cover (Madhavan et al., 2016). To minimise the effect of the spatial variability of solar resources between the locations assessed, only clear-sky periods were considered to elaborate the core part of the proposed calibration method. Clear-sky conditions refer to moments with cloudless sky (i.e. zero Oktas). In order to determine clear-sky periods, the method proposed by Reno and Hansen (2016) was applied. This method detects clear-sky periods within a time-series of global horizontal irradiances, if a set of criteria is met. For a given time-series, these criteria refer to the: (i) mean irradiance; (ii) maximum irradiance; (iii) irradiance variability considering the line length of the points; (iv) series slope variance; and (v) maximum deviation of slope between the observed data and a modelled clear-sky series. If the variables referred for a given time-series are in range with those of a modelled clear-sky irradiance series, then those samples are considered clear-sky periods. In this study, the data from each of the reference solar radiation stations were used to detect clearsky periods. This is due to the reason that minutely observations are required to apply this method and PWS provide 5-minute resolution data. In addition, silicon photodiodes are generally characterised by a saturation region at highirradiance levels, which depends on the series resistance at the terminals of the device and it is different for each sensor (Barber et al., 2017). 
Having obtained the clear-sky periods for each reference stations, common minutely timestamps between the reference and PWS data were selected. This stage produced a time-series, which was then filtered by solar elevations larger than 8 degrees to eliminate timestamps with increased errors related to the cosine response of the instruments and in which the horizon heights might be causing shadowing (Muneer and Gul, 2000). The detection of clear-sky periods was implemented in Python programming using the library pvlib (Holmgren et al., 2018).

\subsection{Clear-sky irradiance modelling}

Clear-sky irradiance, $G_{c s}$, refers to the theoretical GHI at a given location and time with a cloudless sky. The mathematical algorithms, a.k.a. clear-sky radiation models, are modelling the properties and behaviour of the aerosols and gases in the atmosphere to obtain this theoretical GHI. There are multiple models, which vary in the number of input variables and, consequently, in complexity.

In this study, the clear-sky irradiance serves as an input to implement the detection of clear-sky periods. Also, the proposed method for uncertainty correction utilises the clear-sky index, $k_{c}$, which is the ratio of the observed GHI to the GHI under clear sky conditions $\left(k_{c}=G / G_{c s}\right)$. For the development of the model and the results of this article, the clear-sky model developed in Ineichen and Perez (2002) was used. However, given that each clear-sky radiation model proposes different assumptions related the composition of gases in the atmosphere, section 4.4 assesses the differences in the results for one of the PWS based on several clear-sky radiation models for the calculation of $k_{c}$. The models evaluated are: (i) Kasten and Czeplak (1980), which is a simple model using only the solar zenith angle, $z$, and where GHI is defined as per Eq. 1:

$$
G_{c s}=910 \cdot \cos (z)-30,
$$

(ii) Robledo and Soler (2000), another model using $z$ as the single input variable, Eq. 2:

$$
G_{c s}=1159.24 \cdot(\cos z)^{1.179} \cdot \exp (-0.0019 \cdot(90-z)),
$$

(iii) the simplified Solis model (Ineichen, 2008), which is based on the Lambert-Beer relation, uses multiple inputs and is defined as per Eq. 3:

$$
G_{c s}=G_{0} \cdot \exp \left(-\frac{\tau}{\sin ^{g} z}\right) \cdot \sin z,
$$

where $G_{0}$ denotes the extraterrestrial normal incident irradiance, $\tau$ is the total atmospheric optical depth and $g$ are fitting parameters obtained from radiative transfer model calculations; (iv) the Bird model (Bird and Hulstrom, 1981), a more complex model using the aerosol optical depth (AOD) wavelengths at 380 and $500 \mathrm{~nm}$, precipitable water, and atmospheric ozone, among other variables. The AODs required were estimated from a 3-hour historic time-series of AOD measurements at 550 and $1200 \mathrm{~nm}$ following the widely used Angstrom turbidity index (Angstrom, 1961); the data were obtained from ECMWF (2019) for the same time-period than the PWS data. The precipitable water was estimated using the model by Gueymard (1994), which uses the ambient temperature and the relative humidity in the calculation, both are variables available from the 
PWS. The ozone level utilised was the annual mean value (i.e. $0.284 \mathrm{~cm}$ ) at the coordinates of the PWS as provided by ECMWF (2019). And, (v) Ineichen and Perez (2002), the model used for the modelling of the proposed calibration method and that it is defined by Eq. 4 to Eq. 6 .

$$
G_{c s}=c_{g 1} \cdot G_{0} \cdot \cos (z) \cdot \exp \left(-c_{g 2} \cdot A M \cdot\left(f_{h 1}+f_{h 2}(T L-1)\right)\right) \cdot \exp \left(0.01 \cdot A M^{1.8}\right),
$$

where $A M$ is the air mass $(\mathrm{AM}=1 / \cos z), T L$ represents the Linke Turbidity, $h$ the elevation or altitude, $c_{g 1}$ and $c_{g 2}$ are defined by Eq. 5 and $f_{h 1}$ and $f_{h 2}$ are given by Eq. 6 .

$$
\begin{gathered}
c_{g 1}=5.09 e-5 \cdot h+0.868 \text { and } c_{g 2}=3.92 e-5 \cdot h+0.0387 \\
f_{h 1}=\exp (-h / 8000) \text { and } f_{h 2}=\exp (-h / 1250) .
\end{gathered}
$$

There are other clear-sky radiation models in the literature, such as the ESRA model (Rigollier et al., 2000), the REST2 model (Gueymard, 2008), or the McClear model (Lefèvre et al., 2013) and comparative assessments can be found in the literature (Badescu et al., 2012; Engerer and Mills, 2015; Ineichen, 2016). The clear-sky irradiance modelling was partly implemented using the Python library pvlib (Holmgren et al., 2018).

\subsection{Pre-processing of PWS data}

The meteorological data reported by PWS usually requires a level of pre-processing before use. The pre-process tasks may depend on the format and quality of the raw data. The steps of pre-process for PWS data in this study are described below and can serve as a guideline for users of this type of data source. First, a verification of the reporting time of the station is a key step for time-series analysis. PWS data may be reported in local time, coordinated universal time (UTC) or both. When reporting in local time, additional consideration needs to be made for daylight saving time to check if the reporting time corresponds to the summer or winter local time. Second, eliminate timestamps with missing data for the relevant variables, i.e. not a number $(\mathrm{NaN})$ values. For the PWS data in this study, this step was done for irradiance and air temperature. Typical values for missing data can be 'nan', 'NaN', '-999', '-9999', 'inf', '-inf', or a white space character. Finally, for irradiance measurements is important to remove not physically possible or rare observations that can represent outliers. In this article, valid PWS data measurements were identified using the method of the International Commission on Illumination (CIE) as presented by Calça et al. (2019). This method considers valid GHI observations attending to two criteria: (i) $0<G \leq 1.2 \cdot G_{0}$; and (ii) $\mu_{G}-2.57 \sigma_{G} \leq G \leq \mu_{G}+2.57 \sigma_{G}$, where $\mu_{G}$ and $\sigma_{G}$ correspond to the daily mean and standard deviation of GHI observations. The value of 2.57 multiplying the standard deviation corresponds to the $99.5^{\text {th }}$ percentile in a normal probability distribution. Any reported irradiance value not meeting these two criteria were identified as outliers and removed from the dataset.

Having performed the steps above, the time-series of PWS data were ready for the selection of common timestamps with the reference data as described in section 3.1 and illustrated in the flowchart (see Fig. 1). The size of the resulting time-series for each PWS are those indicated as valid data points in Table 2. 


\subsection{Uncertainty correction procedure}

The uncertainty of measurements produced by silicon-photodiode sensors has been a topic of research interest, mainly due to the low-cost solution these sensors offer for land-based measurements. A number of empirical methods have been proposed in the literature to estimate the broadband solar irradiance captured by silicon-photodiode sensors addressing effects related to temperature, spectral mismatch and solar angle of incidence (Augustyn et al., 2004; King et al., 1998; King and Myers, 1997; Vignola et al., 2017; Walter-Shea et al., 2019).

The operating temperature of the solar radiation sensor, $T$, is one of the factors which affects the sensitivity of the measurements (Alados-Arboledas et al., 1995). Generally, in silicon-photodiode pyranometers, temperature-related effects are more prominent in the morning and afternoon, as the average spectral distribution shifts to longer wavelengths (Vignola et al., 2018). However, the influence of temperature in silicon-based irradiance sensors is typically low, around 0.1-0.15\%/ ${ }^{\circ} \mathrm{C}$ (Alados-Arboledas et al., 1995; King et al., 1998). The operating temperature can be measured using thermocouples. Alternatively, for some sensors it can be estimated with the air temperature plus an offset. For example, an offset of $6^{\circ} \mathrm{C}$ can be applied for the silicon-based pyranometer LICOR LI-200 (King et al., 1998). PWS manufacturers may sometimes indicate a temperature coefficient in the specifications sheet. Correction for temperature effects is likely the only correction referred by PWS' manufacturers and can be estimated with Eq. 7.

$$
G_{T}=G \cdot\left[1+\alpha\left(T-T_{0}\right)\right],
$$

where $T_{0}$ is a reference temperature equal to $25^{\circ} \mathrm{C}$ and $T$ denotes the device temperature. The temperature coefficient, $\alpha$, would depend on the sensor. For example ${ }^{1}, 0.082 \% /{ }^{\circ} \mathrm{C}$ for the LICOR LI-200 sensor (King et al., 1998) or $0.12 \% /{ }^{\circ} \mathrm{C}$ for the Davis Instruments 6450 sensor, used in their PWS (Davis Instruments, 2019).

The angle-of-incidence between the sun and the sensor, which corresponds to the solar zenith angle for the GHI, is the factor which affects the most irradiance measurements by silicon-based sensors (Wilbert et al., 2016). PWS producers only provide some increased tolerances for different ranges of incident angles in respect to the cosine response. Simple calibration methods can compensate by multiplying the reading with a constant or linear function of the solar zenith angle as derived from experiments. Existing empirical methods in the literature utilise solar zenith angle to compensate the spectral mismatch and cosine response effects, e.g. (King et al., 1998; King and Myers, 1997; Vignola et al., 2017; Walter-Shea et al., 2019). Using the solar zenith angle, Augustyn et al. (2004) proposed a piece-wise, segmented function to compensate the so-called cat ears' effect at high solar zenith angles. The method developed by King et al. (1998) is used as reference for the calibration methods by Augustyn et al. (2004); Vignola et al. (2017), which add or change parameters. Although the calibration methods mentioned were produced using a LICOR LI-200 pyranometer, the methods can be applicable to other silicon-based pyranometers using Eq. 8 (Augustyn et al., 2004; Wilbert et al., 2015):

\footnotetext{
${ }^{1}$ Mention of manufacturer's name does not imply endorsement of any product over those offered by other manufacturers but it is provided for the convenience of the reader.
} 


$$
G_{\text {cor }}=G_{\text {uncor }} \cdot \frac{F_{\alpha}(T)}{F_{A}(A M) \cdot F_{B}(z) \cdot F_{C}(z)},
$$

where $F_{\alpha}$ is a function depending on the temperature of the device defined by $\left[1+\alpha\left(T-T_{0}\right)\right], F_{A}$ is a polynomial function depending on the air mass given by Eq. 9 and $F_{B}$ (Eq. 10) depends on the solar zenith angle (King et al., 1998). $F_{C}$ is the piece-wise polynomial function depending on the solar zenith angle added by Augustyn et al. (2004) for the cat ear correction, Eq. 11. The method by Vignola et al. (2017) uses a different air mass function, while maintaining the same $F_{\alpha}$ and $F_{B}$ than King et al. (1998).

$$
\begin{gathered}
F_{A}=2.631 \cdot 10^{-4} \cdot A M^{3}-6.319 \cdot 10^{-3} \cdot A M^{2}+5.401 \cdot 10^{-2} \cdot A M+0.932, \\
F_{B}=-4.504 \cdot 10^{-7} \cdot z^{3}+1.357 \cdot 10^{-5} \cdot z^{2}+6.074 \cdot 10^{-4} \cdot z+1, \\
F_{C}= \begin{cases}75^{\circ}<z<81^{\circ} ; & 10.165-0.242 \cdot z+1.603 \cdot 10^{-3} \cdot z^{2} \\
81^{\circ} \leq z<83.2^{\circ} ; & -58.034+1.458 \cdot z-8.99 \cdot 10^{-3} \cdot z^{2} \\
0^{\circ} \leq z \leq 75^{\circ} \vee z \geq 83.2^{\circ} ; & 1 .\end{cases}
\end{gathered}
$$

This article presents a multivariate correction function to estimate the broadband solar irradiance of silicon-photodiode pyranometers used in PWS under all-sky conditions, given that for sensors in these stations, technical specifications (e.g. sensor's response to irradiance, temperature coefficient or calibration constants) are often not readily available. The proposed model is conceived so as to be fed with basic information and data from PWS. The approach is data-driven based on historic data from multiple PWS and high-resolution GHI measurements from thermopile pyranometers. The correction model considers: (i) the device temperature derived from air temperature, (ii) the solar zenith angle, and (iii) the clear-sky index.

In the proposed algorithm, the corrected irradiance $\left(G_{c o r}\right)$ is defined as the actual irradiance reading from the PWS $(G)$ plus an estimated error $(\epsilon)$, which depends on the irradiance, the device temperature and the solar zenith angle, and that it is multiplied by a constant $(\kappa)$ depending on the clear-sky index, Eq. 12:

$$
G_{c o r}=G+\epsilon(G, T, z) \cdot \kappa\left(k_{c}\right) .
$$

$\epsilon$ is defined as per Eq. 13, where $G_{T}$ is the temperature-corrected irradiance estimated with Eq. 7 using an offset of the air temperature for the device temperature $\left(T=T_{a}+6{ }^{\circ} \mathrm{C}\right)$ and a temperature coefficient of $0.12 \% /{ }^{\circ} \mathrm{C}$ (Davis Instruments, 2019). $A$ and $B$ are dimensionless polynomial of third order depending on $z$. The values fitted to obtain the polynomials $A$ and $B$ correspond to the slope and interceptor coefficients, respectively, of a first-order polynomial repeatedly fitted in a function $G_{T}$ vs $\Delta G$ under clear-sky conditions only, where $\Delta G$ is the difference between the irradiance measurements from the reference (thermopile-based) and PWS data $\left(\Delta G=G_{r e f}-G\right)$. 


$$
\epsilon=A(z) \cdot G_{T}(G, T)+B(z) .
$$

$\kappa$ is a coefficient representing an adjusted clear-sky index $\left(k_{c}\right)$ to the $[0,1]$ interval. Eq. 14 is used to obtain $\kappa$ for each observation $i$, where $k_{c, \min }$ and $k_{c, \max }$ correspond to 0.25 and 1 , respectively. The variable is saturated to 1 for $k_{c}$ greater than 1 and to 0 for $k_{c}$ below 0.25 .

$$
\kappa_{i}=\frac{k_{c, i}-k_{c, \text { min }}}{k_{c, \text { max }}-k_{c, \text { min }}},
$$

The amount of data used to compute the fitting coefficients of $A$ and $B$ vary according to the number of stations considered. In this article, two options to estimate these coefficients are considered: (i) climate-specific correction and (ii) PWS hardware-specific correction. The correction attending to climate fitting includes the data from all the PWS in the same climate zone. The hardware fitting option considers the data from all the weather stations with the same producer; information that is often available in the metadata of the PWS. These fitting options, which use multiple stations, intend to create a calibration model able to deal with particular 'bad-fitting' derived from any unhealthy PWS used in the study. The coefficients of the polynomial functions $A$ and $B$ to obtain $\epsilon$ are presented in Table 3 for the different climates and hardware producers of the PWS studied. These coefficients permit the direct application of the correction method.

Table 3: Coefficients for the dimensionless polynomials $A$ and $B$ function of the solar zenith angle provided by climate zone and PWS manufacturer analysed.

\begin{tabular}{lcccccccc}
\hline \multicolumn{7}{c}{ Coefficients } \\
\hline & $A_{0}$ & $A_{1}$ & $A_{2}$ & $A_{3}$ & $B_{0}$ & $B_{1}$ & $B_{2}$ & $B_{3}$ \\
\hline \hline As & -0.929 & $-7.26 \mathrm{E}-03$ & $2.14 \mathrm{E}-04$ & $-1.70 \mathrm{E}-06$ & 997.27 & 6.310 & -0.334 & $1.58 \mathrm{E}-03$ \\
BSk & -0.514 & $-2.77 \mathrm{E}-02$ & $5.61 \mathrm{E}-04$ & $-3.56 \mathrm{E}-06$ & 724.59 & 20.305 & -0.599 & $3.18 \mathrm{E}-03$ \\
Cfa & -1.038 & $4.01 \mathrm{E}-03$ & $-7.59 \mathrm{E}-05$ & $6.44 \mathrm{E}-07$ & 1118.09 & -4.993 & -0.121 & $3.79 \mathrm{E}-04$ \\
Cfb & 0.481 & $-9.45 \mathrm{E}-02$ & $1.71 \mathrm{E}-03$ & $-9.76 \mathrm{E}-06$ & 278.33 & 57.877 & -1.292 & $6.93 \mathrm{E}-03$ \\
Dfb & -0.872 & $-4.48 \mathrm{E}-03$ & $2.15 \mathrm{E}-05$ & $2.07 \mathrm{E}-07$ & 568.238 & 28.316 & -0.682 & $3.30 \mathrm{E}-03$ \\
\hline Producer 1 & -0.963 & $1.05 \mathrm{E}-03$ & $-5.58 \mathrm{E}-05$ & $4.45 \mathrm{E}-07$ & 1007.82 & 3.838 & -0.264 & $1.04 \mathrm{E}-03$ \\
Producer 2 & -0.929 & $-3.12 \mathrm{E}-03$ & $1.62 \mathrm{E}-04$ & $-1.60 \mathrm{E}-06$ & 931.12 & 4.679 & -0.311 & $1.61 \mathrm{E}-03$ \\
\hline
\end{tabular}

\subsection{Evaluation and performance metrics}

In order to evaluate the proposed calibration model in unseen data, a split between training and validation data was done for each station. The training data were the combined data from all stations in the same climate zone or from the same producer, depending on the fitting option. Each station contributed to the training data with $50 \%$ of its clear-sky samples to build the model. The remaining samples, both clear-sky and all-sky instances, were then used as the validation dataset for the statistical analysis presented.

The results and the proposed calibration model are evaluated with: (i) relative mean bias error (rMBE); (ii) relative mean absolute error (rMAE); (iii) relative root mean square error (rRMSE); and (iv) coefficient of determination 
(R-square or $\mathrm{R}^{2}$ ). The rMBE (Eq. 15) is the average error representing a systematic error to under- or overestimate, the rMAE (Eq. 16) provides the magnitude of the error and the rRMSE (Eq. 17) is a measure of the dispersion of the deviations, which weights outliers more heavily than does the rMAE (Larson, 2013).

$$
\begin{gathered}
r M B E=100 \cdot \frac{\frac{1}{n} \sum_{i=1}^{n}\left(x_{o, i}-x_{e, i}\right)}{\frac{1}{n} \sum_{i=1}^{n} x_{o, i}}, \\
r M A E=100 \cdot \frac{\frac{1}{n} \sum_{i=1}^{n}\left|x_{e, i}-x_{o, i}\right|}{\frac{1}{n} \sum_{i=1}^{n} x_{o, i}}, \\
r R M S E=100 \cdot \frac{\sqrt{\frac{1}{n} \sum_{i=1}^{n}\left(x_{e, i}-x_{o, i}\right)^{2}}}{\frac{1}{n} \sum_{i=1}^{n} x_{o, i}},
\end{gathered}
$$

where $x_{e, i}$ and $x_{o, i}$ are the $i$ th estimated and observed values, respectively, and $n$ denotes the size of the sample. All the metrics reported in this article are achieved based on 5-minute instantaneous irradiance samples.

\section{Results}

This section presents the results of the evaluation of the irradiance measurements from PWS and the proposed correction method. First, the pre-corrected irradiance measurements are assessed in section 4.1. Section 4.2 then presents the results for corrected irradiances with both correction fitting options under clear and all-sky conditions. The proposed method is compared to other simple and empiric literature methods in section 4.3. Finally, the variations in the results considering different clear-sky irradiance models as part of the methodology are introduced in section 4.4 .

\subsection{Evaluation of PWS pre-corrected irradiance measure- ments}

The evaluation of the performance metrics of uncorrected irradiance measurements is highly important as it shows the typical uncertainty and errors that PWS data can have without any correction. It also serves as a basis to highlight the importance of calibration methods. Silicon photodiodes are generally calibrated against high precision thermopile pyranometers (e.g. class A according to standard ISO 9060:2018, previously secondary standard under ISO 9060:1990) by the manufacturers under testing laboratory conditions. Typical full-scale uncertainty for thermopile sensors are around 1-3\%, depending on the model and for silicon-photodiodes is typically 5\% (Davis Instruments, 2019).

The average rMBE and rMAE of all the PWS evaluated under clear-sky conditions are $18.4 \%$ and $21.7 \%$, respectively (see Table 4 in the following subsection for a complete set of results). Since irradiance varies in a spatial dimension, the distance between the location of the PWS and the reference site is expected to have an impact on the error metrics. The distribution of the rMAE for clear-sky samples as function of the distance to the reference site for all the PWS is illustrated in Fig. 2. Clear-sky samples were chosen in an attempt to compare all the stations in similar sky conditions. The figure reveals a positive 


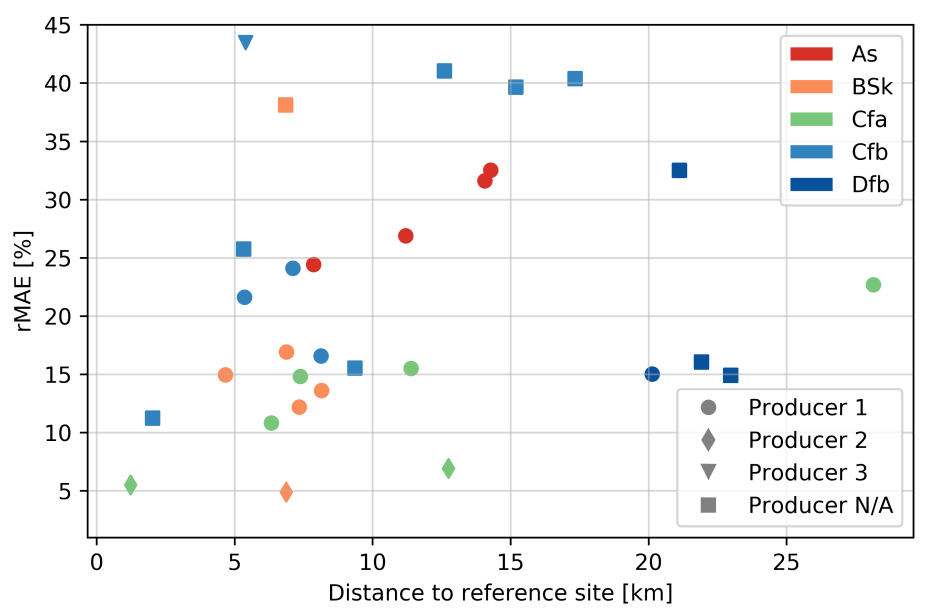

Figure 2: rMAE of uncorrected irradiance, $G$, as function of distance to reference site per climate and producer for all PWS assessed under clear-sky conditions.

relationship between the error and the distance and it has been differentiated by climate zone and producer. It can be observed how clusters can be easier identified by climate zone than by producer. Overall, stations in climate Cfa and BSk present the least average rMAE. There seems to be a nearly linear relationship with distance when looking at the PWS producers; stations from 'Producer 1' (with circle marker), with the existence of outliers. Also, stations by 'Producer 2' (with diamond marker) suggest a more moderate increase in rMAE over distance.

\subsection{Corrected PWS irradiance}

The increased bias of uncorrected PWS irradiance measurements, which has been shown of $18.4 \%$ in average and that can reach over $40 \%$ for some stations under clear-sky conditions, shows the importance of calibration procedures. This subsection presents the results of the proposed correction method. These are first assessed for clear-sky samples, followed by an assessment under all-sky conditions.

\subsubsection{Clear-sky observations}

Following the methodology described in section 3.4, the correction was performed fitting the model with data from each climate zone and PWS hardware producer.

Each fitting option led to different corrected irradiances, which were assessed for each station. Scatter plots illustrating the relationship between the reference measurements and the pre- and post-corrected irradiances using climate fit are shown for several selected personal weather stations in Fig. 3. It can be observed how the overall bias is reduced with the correction model. Also, the saturation of silicon-photodiodes happening at high irradiance levels is partly mitigated with the correction model, for example, station B5 (Fig. 3a), G2 (Fig. 3c), and 

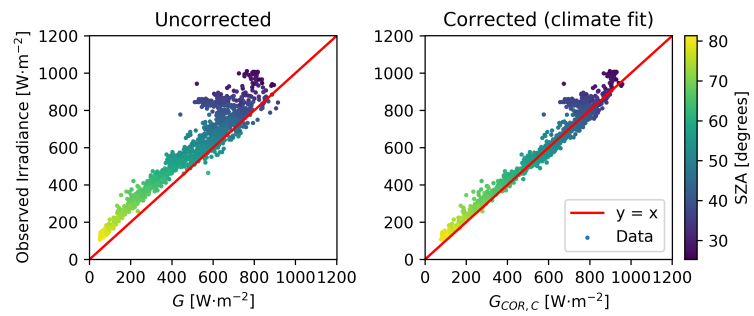

(a) Station B5 - climate BSk
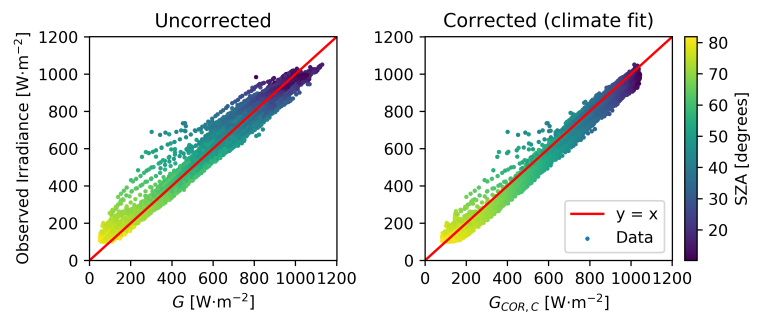

(b) Station D2 - climate Cfa
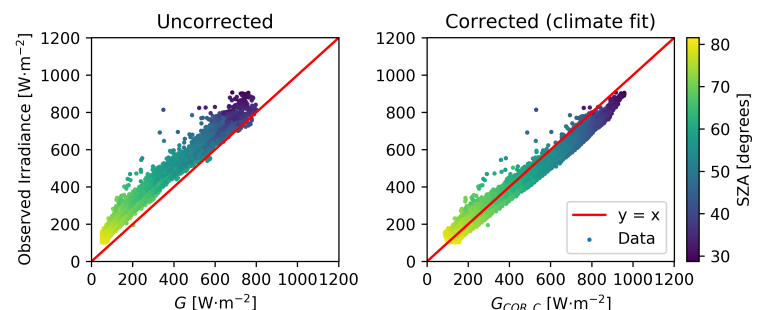

(c) Station G2 - climate Cfb


(d) Station I2 - climate Dfb

Figure 3: Observed (thermopile-based) irradiance versus irradiance before $(G)$ and after correction using climate fitting $\left(G_{c o r, c}\right)$ for a few selected PWS. Data for clear-sky samples only. 


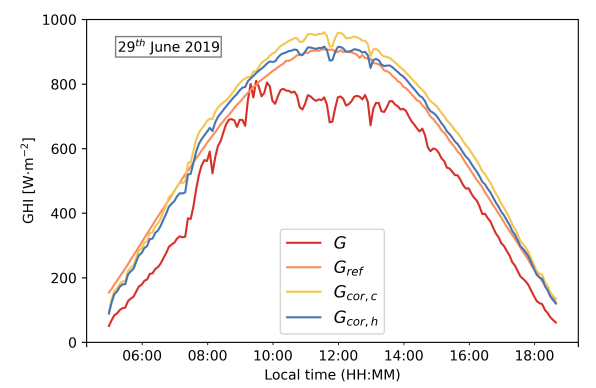

(a)

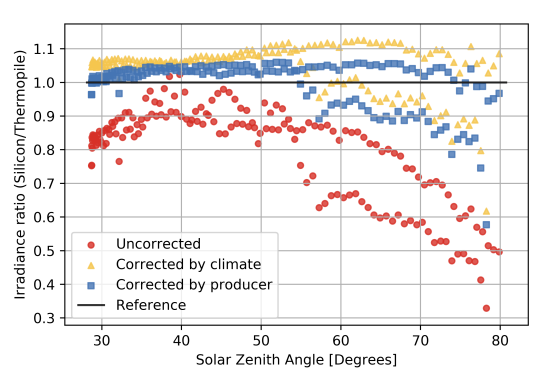

(b)

Figure 4: Global horizontal irradiance time-series (a) and irradiance ratio as function of solar zenith angle (b) for the uncorrected $(G)$, the reference thermopile-based $\left(G_{r e f}\right)$ and the corrected irradiance with climate fit $\left(G_{c o r, c}\right)$ and hardware fit $\left(G_{c o r, h}\right)$. Data for station G2 in a clear-sky day, $29^{\text {th }}$ June 2019.

I2 (Fig. 3d). The correction model achieves a more robust, compact dataset even in PWS that perform well, such as station D2 (Fig. 3b).

Figure 4 illustrates how the corrected irradiance $\left(G_{c o r}\right)$ translates into a time-series for a given day and weather station. The uncorrected and corrected time series can be seen in Fig. 4a, where it can be observed the saturation of the silicon photodiode in the uncorrected measurements $(G)$ at high irradiance levels starting around $800 \mathrm{~W} \cdot \mathrm{m}^{-2}$. As anticipated in the scatter plot for the same station (Fig. 3c), the saturation is compensated in the corrected series. It is worth noting how both fitting options of the calibration model improve the initial GHI observations and are closer to the reference series. Nevertheless, since the corrected series are based on the uncorrected readings, sudden irradiance dips and swells present in the raw measurement transfer to the corrected values.

For the same day and station, Fig. 4b illustrates the irradiance ratio (i.e. PWS (silicon) over reference (thermopile)) for the raw measurements and the corrected series of the calibration model. It can be observed how the irradiance ratios for both corrected options remain approximately constant around unity for solar zenith angles below 50-60 ${ }^{\circ}$. For the uncorrected data, the saturation of the silicon-photodiode sensor is noticeable at the lower range of solar zenith angles, which are the moments with the highest irradiance levels. Concerning the cosine response at higher solar zenith angles, the corrected series are less penalised by the cosine response over 60 degrees than the uncorrecteced irradiance values, which drop significantly at the highest solar zenith angles.

The mean and standard deviation of the evaluation metrics for the 30 stations analysed are presented in Table 4 under clear-sky observations and for both fitting options. In the proposed calibration models, the average errors of the corrected data under clear-sky conditions are the following: $\mathrm{rMBE}, 3.8 \%$ and $1.9 \%$; rMAE, $10.4 \%$ and $7.7 \%$; rRMSE, $13.4 \%$ and $10.6 \%$ and the coefficients of determination are 0.90 . These metrics represent a substantial improvement compared to uncorrected data. Although, the differences between fitting options are not large, the model fitted with PWS data from the same hardware producer obtains better performance. 
Considering the error metrics from individual PWS, station $\mathrm{C} 1$ presented the largest error in its uncorrected form (rMBE: 41.0\%; rMAE: 41.0\%; rRMSE: $41.5 \%$ and R-square: 0.89 ) and the calibration method with climate fit more than halves the errors (rMBE: 15.3\%; rMAE: 15.4\%; rRMSE: $16.9 \%$ and Rsquare: 0.90). On the contrary, station D2 ranked the best PWS without correction (rMBE: 1.1\%; rMAE: 5.5\%; rRMSE: $7.1 \%$ and R-square: 0.98) as observed in the uncorrected scatter plot (see Fig. 3b), the correction method with climate fit still improves those performance metrics in terms of rRMSE and coefficient of determination (rMBE: $-4.6 \%$; rMAE: $5.6 \%$; rRMS: $6.7 \%$ and R-square: 0.99). A breakdown of the performance metrics per climate zone and per hardware producer are reported below.

Table 4: Mean and standard deviation of the evaluation metrics for the $30 \mathrm{PWS}$ in the study for uncorrected $(G)$, temperature-corrected $\left(G_{T}\right)$ data and the correction method with climate fit $\left(G_{c o r, c}\right)$ and hardware fit $\left(G_{c o r, h}\right)$. Observations under clear-sky.

\begin{tabular}{lcccccccc}
\hline & \multicolumn{2}{c}{ rMBE (\%) } & \multicolumn{2}{c}{ rMAE (\%) } & \multicolumn{2}{c}{ rRMSE (\%) } & \multicolumn{2}{c}{ R-square } \\
\hline $\begin{array}{l}\text { Correction } \\
\text { Method }\end{array}$ & Mean & $\begin{array}{c}\text { Std. } \\
\text { Dev. }\end{array}$ & Mean & $\begin{array}{c}\text { Std. } \\
\text { Dev. }\end{array}$ & Mean & $\begin{array}{c}\text { Std. } \\
\text { Dev. }\end{array}$ & Mean & $\begin{array}{r}\text { Std. } \\
\text { Dev. }\end{array}$ \\
\hline \hline$G$ & 18.4 & 11.1 & 21.7 & 11.1 & 25.6 & 12.3 & 0.79 & 0.20 \\
$G_{T}$ & 18.1 & 11.2 & 21.5 & 11.2 & 25.4 & 12.4 & 0.79 & 0.20 \\
$G_{c o r, c}$ & 3.8 & 8.8 & 10.4 & 6.2 & 13.4 & 7.5 & 0.90 & 0.12 \\
$G_{c o r, h}$ & 1.9 & 5.1 & 7.7 & 4.2 & 10.6 & 6.1 & 0.90 & 0.13 \\
\hline
\end{tabular}

The application of the correction model with data from sensors in the same climate zone can highlight particular meteorological characteristics with performance implications, such as similar annual rainfall or temperature. Soiling in the sensors and temperature-related effects may be reflected when using climatespecific fitting. Table 5 presents the overall evaluation metrics for each of the Köppen climate zones with PWS evaluated.

Similarly to the observed in Fig. 2 as part of the evaluation of uncorrected data, humid subtropical (Cfa) and dry semi-arid (BSk) are also the climate zones with the least errors after applying the correction model per climate. The tropical savanna (As) climate obtained the largest errors overall. This could be related to the different locations of the PWS compared to the reference station. In the island of Hawaii (location of those weather stations), cloud formation is diverse due to the presence of mountains and highly depends on the prevalent winds from the Pacific ocean. Therefore, samples identified as clear-sky in the reference location, may not necessarily relate to clear-sky observations at the PWS' locations. The model for oceanic, marine west coast $(\mathrm{Cfb})$ climate reports the highest deviations in its performance metrics, what could be related with the diversity of locations involved in assessment evaluation, i.e. 10 stations across 4 reference sites.

In relation to the correction method per PWS producer, sensor-specific characteristics with performance implications (e.g. sensor's response to irradiance or internal resistance) could be reflected when fitting the calibration model using PWS data from the same producer regardless of their location. Table 6 reports the average evaluation metrics for the correction method fitted with the data 
Table 5: Mean and standard deviation of the error metrics per climate zone for the corrected irradiance using climate fit $\left(G_{c o r, c}\right)$. Observations under clear-sky conditions.

\begin{tabular}{lcccccccc}
\hline & \multicolumn{2}{c}{ rMBE (\%) } & \multicolumn{2}{c}{ rMAE (\%) } & \multicolumn{2}{c}{ rRMSE (\%) } & \multicolumn{2}{c}{ R-square } \\
\hline Climate Zone & Mean & $\begin{array}{c}\text { Std. } \\
\text { Dev. }\end{array}$ & Mean & $\begin{array}{l}\text { Std. } \\
\text { Dev. }\end{array}$ & Mean & $\begin{array}{l}\text { Std. } \\
\text { Dev. }\end{array}$ & Mean & $\begin{array}{c}\text { Std. } \\
\text { Dev. }\end{array}$ \\
\hline \hline $\begin{array}{l}\text { Tropical } \\
\text { Savanna (As) }\end{array}$ & 9.3 & 3.3 & 15.8 & 1.8 & 22.2 & 2.2 & 0.64 & 0.08 \\
\hline $\begin{array}{l}\text { Dry Semi-Arid } \\
\text { BSk) }\end{array}$ & 3.7 & 7.0 & 7.8 & 6.4 & 10.2 & 7.6 & 0.94 & 0.06 \\
\hline $\begin{array}{l}\text { Humid } \\
\text { Subtropical (Cfa) }\end{array}$ & 0.3 & 3.1 & 5.4 & 1.4 & 7.4 & 1.7 & 0.97 & 0.01 \\
\hline $\begin{array}{l}\text { Oceanic, Marine } \\
\text { West Coast (Cfb) }\end{array}$ & 5.1 & 12.7 & 13.8 & 6.4 & 16.2 & 7.5 & 0.93 & 0.06 \\
\hline $\begin{array}{l}\text { Warm Summer } \\
\text { Continental (Dfb) }\end{array}$ & 0.1 & 4.0 & 8.3 & 3.2 & 11.2 & 4.2 & 0.94 & 0.02 \\
\hline
\end{tabular}

differentiated by PWS producer ${ }^{2}$. It was assumed that PWS producers utilise the same solar radiation sensors for all the PWS series in their portfolio. While the results are relatively good for 'Producer 1' and 'Producer 2', both rMBE are within a $5 \%$ tolerance band, it can be observed how the rest of metrics for 'Producer 1' suggest larger errors under clear-sky conditions. The error metrics for 'Producer 3' are not reported since the data correspond to a single PWS.

Table 6: Mean and standard deviation of the error metrics per producer for the corrected irradiance using hardware fit $\left(G_{c o r, h}\right)$. Observations under clear-sky conditions.

\begin{tabular}{|c|c|c|c|c|c|c|c|c|}
\hline \multirow[b]{2}{*}{ PWS hardware } & \multicolumn{2}{|c|}{ rMBE (\%) } & \multicolumn{2}{|c|}{ rMAE (\%) } & \multicolumn{2}{|c|}{ rRMSE (\%) } & \multicolumn{2}{|c|}{ R-square } \\
\hline & Mean & $\begin{array}{l}\text { Std. } \\
\text { Dev. }\end{array}$ & Mean & $\begin{array}{l}\text { Std. } \\
\text { Dev. }\end{array}$ & Mean & $\begin{array}{l}\text { Std. } \\
\text { Dev. }\end{array}$ & Mean & $\begin{array}{l}\text { Std. } \\
\text { Dev. }\end{array}$ \\
\hline Producer 1 & 3.1 & 5.1 & 8.1 & 4.6 & 11.3 & 6.7 & 0.88 & 0.14 \\
\hline Producer 2 & -3.1 & 1.9 & 5.6 & 0.9 & 7.3 & 1.4 & 0.97 & 0.02 \\
\hline
\end{tabular}

\subsubsection{All-sky observations}

This subsection introduces the results under all-sky conditions. The evaluation metrics reported are only of those PWS stations within a $5 \mathrm{~km}$ distance to their reference site. This is due to the acute solar radiation variability that can occur in space under all-sky conditions for the instantaneous irradiance measurements in two close locations. Therefore, the stations assessed under all-sky conditions

\footnotetext{
${ }^{2}$ Neither the authors nor their organisation (Queen's University Belfast) has any relationship with the manufacturers of the devices described.
} 
are: B1, D2 and G1. It is worth noting that stations B1 and G1 may be subject to seasonality errors since their available data includes less than 100 days.

The effect of the correction method is presented for station B1 in Fig. 5, where it can be observed that the correction under all-sky conditions reduces the overall bias, produces a more compact dataset and decreases the density of samples scattered. Although outliers remain in the corrected form, it cannot be concluded from the data whether these more dispersed samples correspond to uncertainty from PWS under all-sky conditions or from changing atmospheric conditions between the locations of the reference station and PWS.
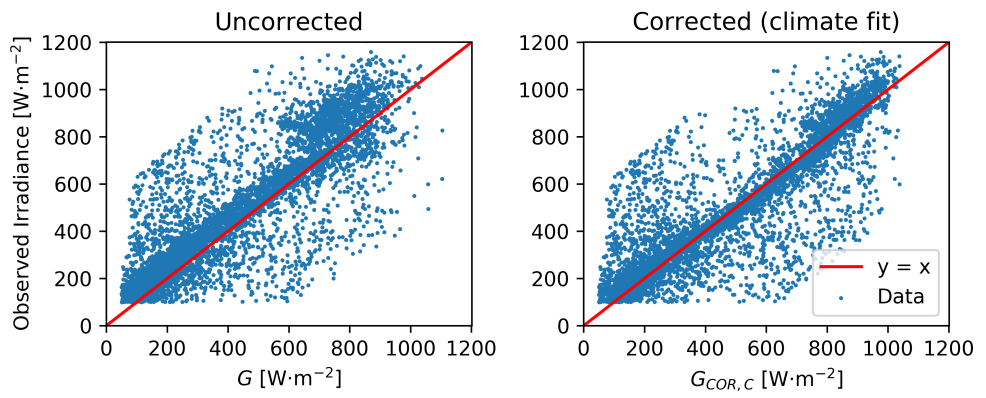

Figure 5: Observed (thermopile-based) irradiance versus irradiance before $(G)$ and after correction using climate fitting $\left(G_{c o r, c}\right)$ for station B1 under all-sky conditions.

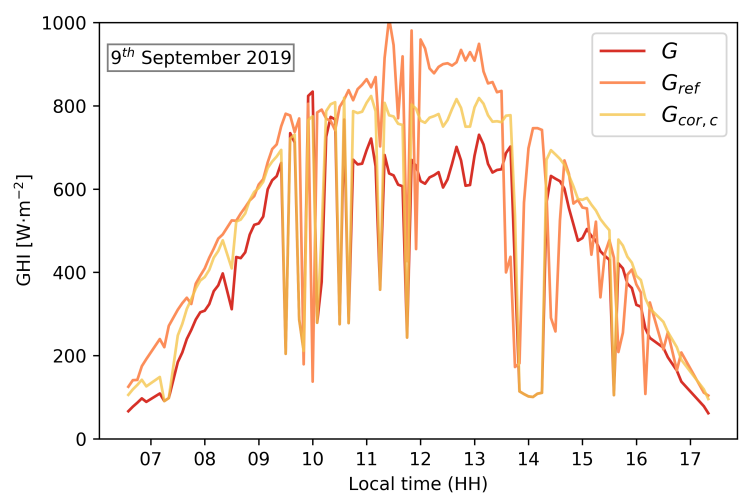

Figure 6: Global horizontal irradiance time series of the uncorrected $(G)$, the reference thermopile-based $\left(G_{r e f}\right)$ and the corrected irradiance with climate fit $\left(G_{c o r, c}\right)$. All-sky conditions data for station B1, $9^{\text {th }}$ September 2019.

In this respect, the evolution of the irradiance for a given day under all-sky conditions is illustrated in Fig. 6, where a selected day with intermittent sky for the same station is shown. It can be seen how that day commences with fairly clear-sky conditions until $9 \mathrm{~h}$, where the corrected irradiance $\left(G_{c o r, c}\right)$ is closer to the reference time series $\left(G_{r e f}\right)$ than the uncorrected measurements reported by the PWS $(G)$. Similarly, the corrected irradiance is closer to the reference data 
between $12 \mathrm{~h}$ to $14 \mathrm{~h}$, what seems to be moments of clearer sky conditions. The first sudden drop of irradiance, happening around 9:30h, is only observed in the PWS data and not in the reference site and produces a difference around 600 $\mathrm{W} \cdot \mathrm{m}^{-2}$ in that instant. The following sudden drop of irradiance, shortly after, is reported by both sensors. Throughout that day, it can be observed how there are rapid, abrupt changes in the samples reported, which differ and coincide at times, between the reference and PWS observations. Therefore, the large differences reported in the 5-minute instantaneous irradiance measurements could be influenced by local cloud cover or atmospheric phenomena present at different times in such locations over a long period of time.

Table 7: Evaluation metrics for selected PWS under all-sky conditions for uncorrected $(G)$ and temperature-correction $\left(G_{T}\right)$ data and the correction method with climate fit $\left(G_{c o r, c}\right)$ and hardware fit $\left(G_{c o r, h}\right)$.

\begin{tabular}{cccccccccc}
\hline \multicolumn{1}{c}{ rMBE (\%) } & \multicolumn{7}{c}{ rMAE (\%) } \\
\hline PWS & $G$ & $G_{T}$ & $G_{c o r, c}$ & $G_{c o r, h}$ & PWS & $G$ & $G_{T}$ & $G_{c o r, c}$ & $G_{c o r, h}$ \\
\hline \hline B1 & 12.9 & 12.1 & 3.5 & 3.2 & B1 & 28.5 & 28.3 & 24.4 & 24.3 \\
D2 & 5.3 & 4.9 & -2.5 & -2.7 & D2 & 15.2 & 15.2 & 16.8 & 16.6 \\
G1 & 19.1 & 18.9 & 1.1 & - & G1 & 23.3 & 23.2 & 22.3 & - \\
\hline Mean & 12.4 & 12.0 & 0.7 & 0.3 & Mean & 22.3 & 22.2 & 21.1 & 20.4 \\
\hline \multicolumn{4}{c}{ rRMSE } & $(\%)$ & & \multicolumn{5}{c}{ R-square } \\
\hline PWS & $G$ & $G_{T}$ & $G_{c o r, c}$ & $G_{c o r, h}$ & PWS & $G$ & $G_{T}$ & $G_{c o r, c}$ & $G_{c o r, h}$ \\
\hline \hline B1 & 44.7 & 44.7 & 43.6 & 43.5 & B1 & 0.49 & 0.49 & 0.50 & 0.50 \\
D2 & 28.1 & 28.2 & 28.2 & 28.1 & D2 & 0.83 & 0.83 & 0.83 & 0.83 \\
G1 & 34.6 & 34.5 & 34.1 & - & G1 & 0.76 & 0.76 & 0.74 & - \\
\hline Mean & 35.8 & 35.8 & 35.3 & 35.8 & Mean & 0.69 & 0.69 & 0.69 & 0.67 \\
\hline
\end{tabular}

The evaluation metrics are presented in Table 7, where it is shown that, on average, both corrected options significantly reduce the rMBE. Both fits of the correction model for the 3 stations report an $\mathrm{rMBE}$ within a $\pm 5 \%$ tolerance band. However, the rMAE, rRMSE and R-square do not vary as much and only observe a moderate improvement of about $1-4 \%$ depending on the metric and fitting option. The station D2 is, as occurred for clear-sky conditions, the station with the best operation under all-sky conditions with the best performance metrics among the stations assessed.

\subsection{Comparison against other existing methods}

This section presents the results of comparing the proposed calibration method to other available methods, both simple and complex. The methods evaluated are: (i) constant correction; (ii) linear correction; (iii) the method developed in King et al. (1998); and (iv) the method by Augustyn et al. (2004). The constant and linear correction methods were obtained from the relationship between the irradiance readings from the PWS and reference site under clear-sky conditions. The methods iii and iv were directly applied using Eq. 9 to Eq. 11. Although these methods were developed using the LICOR LI-200 pyranometers, they are 
often used for all kind of silicon-photodiode sensors permitting a comparison with the proposed method using Eq. 8 (Wilbert et al., 2015).

The mean and standard deviation of the performance metrics under all-sky conditions are presented in Table 8 for the same 3 stations previously assessed. Since the method by Augustyn et al. (2004) uses the King et al. (1998) method and expands it with an equation for cat ear irradiance correction at large solar zenith angles, the metrics for Augustyn et al. (2004) are presented in the table below as the reported metrics were very similar.

Table 8: Comparison of mean and standard deviation of the performance metrics under all-sky conditions: uncorrected data $(G)$, temperature correction $\left(G_{T}\right)$, existing literature methods and proposed correction methods with climate fit $\left(G_{c o r, c}\right)$ and hardware fit $\left(G_{c o r, h}\right)$.

\begin{tabular}{lcccccccc}
\hline & \multicolumn{2}{c}{ rMBE (\%) } & \multicolumn{2}{c}{ rMAE (\%) } & \multicolumn{2}{c}{ rRMSE (\%) } & \multicolumn{2}{c}{ R-square } \\
\hline Calibration method & Mean & $\begin{array}{c}\text { Std. } \\
\text { Dev. }\end{array}$ & Mean & $\begin{array}{c}\text { Std. } \\
\text { Dev. }\end{array}$ & Mean & $\begin{array}{c}\text { Std. } \\
\text { Dev. }\end{array}$ & Mean & $\begin{array}{l}\text { Std. } \\
\text { Dev. }\end{array}$ \\
\hline \hline Uncorrected, $G$ & 12.4 & 5.6 & 22.3 & 5.5 & 35.8 & 6.8 & 0.69 & 0.15 \\
\hline Temperature corr., $G_{T}$ & 12.0 & 5.7 & 22.2 & 5.4 & 35.8 & 6.8 & 0.69 & 0.15 \\
\hline Constant correction & 2.6 & 8.5 & 21.9 & 3.8 & 34.5 & 6.6 & 0.69 & 0.15 \\
\hline Linear correction & 3.3 & 8.2 & 21.9 & 3.7 & 34.6 & 6.5 & 0.68 & 0.14 \\
\hline $\begin{array}{l}\text { King et al.(1998) and } \\
\text { Augustyn et al.(2004) }\end{array}$ & 7.9 & 5.7 & 21.9 & 5.3 & 35.6 & 6.8 & 0.69 & 0.15 \\
\hline $\begin{array}{l}\text { Proposed with } \\
\text { climate fit, } G_{c o r, c}\end{array}$ & 0.7 & 2.5 & 21.1 & 3.2 & 35.3 & 6.3 & 0.69 & 0.14 \\
\hline $\begin{array}{l}\text { Proposed with } \\
\text { hardware fit, } G_{c o r, h}\end{array}$ & 0.3 & 2.9 & 20.4 & 3.8 & 35.8 & 7.7 & 0.67 & 0.16 \\
\hline
\end{tabular}

Among the benchmarked methods, the method by Augustyn et al. (2004) built on the work of King et al. (1998) performs in range with the simple constant or linear correction. Although, it has reports a higher rMBE (i.e. 7.9\%) than the simple methods, which is outside of a $\pm 5 \%$ tolerance band and it is considered the typical acceptance band for bias. Between the simple methods, constant correction reports better accuracy than a linear calibration based on the solar zenith angle. The proposed method fitted with data from the same manufacturer (i.e. hardware fit) outperforms the rest of the methods. With regard to the rMAE and rRMSE, the methods tested do present similar performance than the uncorrected data.

\subsection{Sensitivity of results due to clear-sky irradiance mod- elling}

Since the proposed calibration method utilises the clear-sky index, $k_{c}$, and this is estimated from the clear-sky irradiance, $G_{c S}$, the variation in the error metrics when utilising different clear-sky radiation models is presented below. As introduced in section 3.2, four clear-sky models are compared to the one used in the model. Table 9 introduces the error metrics for the station D2 under all-sky 
observations using the climate-specific polynomial fit of the model. The results show that the selection of the clear-sky radiation model have overall a moderate impact. The most significant effect is reported in the rMBE with differences up to $3.8 \%$ between models, the rMAE and rRMSE show maximum differences around $2 \%$ and the R-square observes minimal changes. The Ineichen and Perez (2002) model used as part of the correction procedure ranks second, only outperformed by the Robledo and Soler (2000) model and closely followed by the Bird and Hulstrom (1981) model.

Table 9: Comparison of error metrics for different clear-sky radiation models to implement the proposed correction model. Data for station D2 under all-sky observations using the correction model fitted with climate-specific data.

\begin{tabular}{lcccc}
\hline Clear-sky model & rMBE (\%) & rMAE (\%) & rRMSE (\%) & R-square \\
\hline Bird and Hulstrom (1981) & -2.8 & 16.9 & 28.3 & 0.83 \\
Ineichen and Perez (2002) & -2.5 & 16.8 & 28.2 & 0.83 \\
Kasten and Czeplak (1980) & -4.8 & 17.8 & 29.0 & 0.83 \\
Robledo and Soler (2000) & -1.6 & 16.2 & 27.9 & 0.83 \\
Simpl. Solis, Ineichen (2008) & -5.3 & 18.3 & 29.3 & 0.82 \\
\hline
\end{tabular}

\section{Discussion}

The assessment of uncorrected clear-sky irradiance measurements of the siliconphotodiode sensors used in PWS showed that these are subject to large errors, which can reach over $40 \%$ rMBE and rMAE. Overall, the mean rMBE for uncorrected clear-sky instances was reported of $18.4 \%$, which is near to the $\pm 15 \%$ tolerance indicated by King et al. (1998). The distance from each PWS to the reference site revealed a positive correlation with the mean absolute error, which was better identified by climate than by hardware producer. The correction considering temperature-induced effects, which is the only correction often proposed by the manufacturers, still presented high uncertainties, and slightly reduced the errors.

The proposed calibration method has been presented with two fitting options: (i) PWS in the same climate zone, and (ii) those PWS with the same producer of hardware. Both correction methods achieved a substantial reduction in the error metrics under clear-sky conditions. After correction, rMBE were within a $\pm 5 \%$ tolerance, rMAE were up to $10.4 \%$ and rRMSE up to $13.4 \%$ as observed in Table 4. A breakdown of the results per climate zone and producer was also presented, where most of the climates and both producers achieved clear-sky, corrected irradiance samples with a bias within a $\pm 5 \%$ tolerance (see Table 5 and Table 6). It was also observed that the corrected irradiance time series deal well with the characteristic saturation of silicon-photodiodes at high irradiance levels. In addition, the corrected time series are less penalised by the cosine response at higher solar zenith angles than the uncorrected data.

Under all-sky conditions, the proposed method showed a significant better performance regarding the rMBE. However, the rMAE and rRMSE remained high and are only improved around 1-4\%, depending on the metric, fitting option and station. The observation of the intra-daily evolution of solar irradiance 
for a given station (see Fig. 6) can support the idea that the high rMAE and rRMSE may be related to the high solar irradiance variability in different nearby locations with changing conditions of the sky.

The proposed calibration method was compared to the existing literature methods which could be implemented without technical data (e.g. calibration constants) derived from laboratory measurements. A simple constant, linear correction and the model by King et al. (1998) with the addition of Augustyn et al. (2004) were used in the comparison. The proposed method outperformed those from the literature in both fitting options for all-sky samples. It is worth noting how the literature method by King et al. (1998) and Augustyn et al. (2004) still reports high rMAE and rRMSE, which is in range with the proposed method. This can, again, support the thesis in which those large errors may refer to the spatial variability of solar irradiance between the locations of the reference and personal weather stations. It is necessary to remember that the data assessed in this article correspond to 5-minute instantaneous irradiance measurements.

Overall, the performance both under clear and all-sky conditions of the proposed model in terms of bias are in alignment with those from stand-alone silicon photodiode pyranometers for GHI measurements in other studies, where the accuracies are within a $\pm 5 \%$ band compared to thermopile pyranometers (King and Myers, 1997; Sengupta et al., 2012; Vignola et al., 2017; Walter-Shea et al., 2019).

With regards to the sensitivity of the clear-sky radiation model to obtain the constant $\kappa$, the selection of different methods has shown a moderate impact on the results. It is worth noting that more complex clear-sky radiation models, do not necessarily perform better. For example, Robledo and Soler (2000) is considered a simple model, which uses solar zenith angle as the only input variable, and outperforms the rest of assessed models, from very simple to complex ones. It can be also observed how a high deviation in clear-sky models does not affect much the results. That is the case for the model by Kasten and Czeplak (1980), which peaks at $880 \mathrm{~W} \cdot \mathrm{m}^{-2}$ (see Eq. 1) and can represent a high systematic underestimation of clear-sky irradiance. The proposed calibration model deals with the sub-estimation effect, as the detection of clear-sky periods utilises the slope of irradiance measurements and $\kappa$ adjusts the clear-sky index to the data. The clear-sky radiation model used, i.e. Ineichen and Perez (2002), ranked second.

While the study takes a data-driven approach, the polynomial coefficients for several climate zones and the PWS producers of the stations assessed are given in Table 3 to extend the applicability of the method without the need for high-quality reference data. Since PWS data are having an increasing popularity and usage in research studies, the users of these data can implement the proposed calibration method for irradiance observations with only accessing basic metadata. In addition, users of PWS data can use the pre-processing steps described in section 3.3 as a guideline.

\section{Conclusions and Further Work}

The aim of this article was to assess the accuracy of solar irradiance measurements from PWS so that data users can be aware of their performance without 
any correction. We examined solar irradiance data from 30 PWS located worldwide and compared them to well-maintained thermopile pyranometers. The results showed how uncorrected data are subject to significant, large errors.

A calibration method to obtain the broadband irradiance was proposed for all-sky conditions based on the temperature of the sensor, solar zenith angle and clear-sky index. The data-driven method allows fitting the model based on different data. The model was built using data from sites in the same climate zone and with the same hardware producer, where the latter reported better performance. This proposed method resulted in substantial improvement of the accuracy under clear-sky conditions and helped deal with the saturation of silicon-photodiodes at high irradiance levels and with the cosine response of the devices at large (over 60 degrees) solar zenith angles. The calibration model permitted increase the accuracy with mean bias error reduced from $18.4 \%$ to $2.8 \%$ for clear-sky samples. Under all-sky conditions, the calibration method reported a large reduction of the MBE, while the rMAE and rRMSE remained high with a moderate improvement about $1-4 \%$ depending on the metric and fitting option.

Overall, the proposed calibration method in both fitting options resulted in rMBE within a $\pm 5 \%$ range, which is similar to other studies and the typical tolerances indicated by manufacturers. However, rMAE and rRMSE remained high for all-sky samples and it cannot be concluded from the data whether this is the result of the uncertainty in the equipment and/or operation of PWS or from the spatial displacement between the stations studied. When compared to existing calibration methods from the literature, the proposed correction outperformed the rest of the methods. The calibration method presented in this article can be used to remove systematic errors from the irradiance measurements and can be directly applied using basic PWS data. The use of these data should be carefully evaluated with regards to the potential high uncertainty that these measurements can be subject. This is specially important since PWS data are observing an increasing popularity and use in research studies. While PWS cannot replace stand-alone, traditional pyranometers, they represent an open data source that can, still, complement land-based solar radiation monitoring with higher spatial resolution than that initially available from high-quality pyranometers.

The scope of this study was limited in terms of comparing irradiance measurements at the same locations. This limitation may evidence the large errors observed under all-sky conditions. Thus, further work is required to assess the actual uncertainty of PWS data under all-sky conditions by comparing thermopile pyranometers and PWS irradiance observations at the same locations.

\section{Acknowledgment}

The authors would like to thank all the individuals that voluntarily make publicly available the data from their Personal Weather Stations on the Internet. The authors also wish to acknowledge the support of the INTERREG VA SPIRE2 project. This research was supported by the European Union's INTERREG VA Programme (Grant No. INT-VA/049), managed by the Special EU Programmes Body (SEUPB). The views and opinions expressed in this document do not necessarily reflect those of the European Commission or the 
Special EU Programmes Body.

\section{References}

Al-Rasheedi, M., Gueymard, C. A., Ismail, A. and Hussain, T. (2018), 'Comparison of two sensor technologies for solar irradiance measurement in a desert environment', Sol. Energy 161, 194-206.

Alados-Arboledas, L., Batlles, F. J. and Olmo, F. J. (1995), 'Solar radiation resource assessment by means of silicon cells', Sol. Energy 54(3), 183-191.

Angstrom, A. (1961), 'Techniques of determining the turbidity of the atmosphere', Tellus 13(2), 214-223.

Augustyn, J., Geer, T., Stoffel, T., Kessler, R., Kern, E., Little, R., Vignola, F. and Boyson, B. (2004), Update of algorithm to correct direct normal irradiance measurements made with a rotating shadow band pyranometer, in R. Campbell-Howe and B. Wilkins-Crowder, eds, 'Proc. Amercian Sol. Energy Soc.', Boulder, Colorado, USA, pp. 295-302.

Badescu, V., Gueymard, C. A., Cheval, S., Oprea, C., Baciu, M., Dumitrescu, A., Iacobescu, F., Milos, I. and Rada, C. (2012), 'Computing global and diffuse solar hourly irradiation on clear sky. Review and testing of 54 models', Renew. Sustain. Energy Rev. 16(3), 1636-1656.

URL: http://dx.doi.org/10.1016/j.rser.2011.12.010

Barber, C., López, P. and Martínez, G. (2017), 'Commercial photodiode suitability for solar simulator light monitoring', E3S Web Conf. - Proc. Eur. Sp. Power Conf. 2016 16, 16005.

Bedrina, T., Parodi, A., Quarati, A. and Clematis, A. (2012), 'ICT approaches to integrating institutional and non-institutional data services for better understanding of hydro-meteorological phenomena', Nat. Hazards Earth Syst. Sci. 12(6), 1961-1968.

Bird, R. E. and Hulstrom, R. L. (1981), 'A simplified clear sky model for direct and diffuse insolation on horizontal surfaces'.

URL: www.nrel.gov/docs/legosti/old/761.pdf

Bottaccioli, L., Estebsari, A., Patti, E., Pons, E. and Acquaviva, A. (2019), 'Planning and real-time management of smart grids with high PV penetration in Italy', Proc. Inst. Civ. Eng. - Eng. Sustain. 172(6), 272-282.

Calça, M., Raniero, M., Fernando, D., Rodrigues, S. and Dal, A. (2019), 'Outliers detection in a quality control procedure for measurements of solar radiation', IEEE Lat. Am. Trans. 17(11), 1815-1822.

Colle, S. (2019), 'Basic measurements of radiation at station Florianopolis (201908)'.

URL: https://doi.pangaea.de/10.1594/PANGAEA.905820 
Davis Instruments (2019), 'Specifications Sheet for solar radiation sensor 6450 - Vantage Pro2 accessories'.

URL: www.davisinstruments.com/product_documents/weather/spec_sheets /6450_SS.pdf

De Vos, L., Leijnse, H., Overeem, A. and Uijlenhoet, R. (2017), 'The potential of urban rainfall monitoring with crowdsourced automatic weather stations in Amsterdam', Hydrol. Earth Syst. Sci. 21(2), 765-777.

Dehara, K. (2019), 'Basic measurements of radiation at station Fukuoka (2019$07)^{\prime}$.

URL: https://doi.pangaea.de/10.1594/PANGAEA.905630

Desta, A. A., Courbin, P., Sciandra, V. and George, L. (2017), 'Gaussian-based smoothing of wind and solar power productions using batteries', Int. J. Mech. Eng. Robot. Res. 6(2), 154-159.

Engerer, N. A. and Mills, F. P. (2015), 'Validating nine clear sky radiation models in Australia', Sol. Energy 120, 9-24.

European Centre for Medium Range Weather Forecasts (ECMWF) (2019), 'The Copernicus atmosphere monitoring service (CAMS) all-sky radiation service'. URL: www.soda-pro.com

Gharesifard, M., Wehn, U. and van der Zaag, P. (2017), 'Towards benchmarking citizen observatories: Features and functioning of online amateur weather networks', J. Environ. Manage. 193, 381-393.

URL: $h t t p: / / d x$. doi.org/10.1016/j.jenvman.2017.02.003

Gueymard, C. A. (1994), 'Analysis of monthly average atmospheric precipitable water and turbidity in Canada and northern United States', Sol. Energy 53(1), 57-71.

Gueymard, C. A. (2008), 'REST2: High-performance solar radiation model for cloudless-sky irradiance, illuminance, and photosynthetically active radiation - Validation with a benchmark dataset', Sol. Energy 82(3), 272-285.

Hodgetts, G. (2017), 'Basic measurements of radiation at station Camborne (2017-07)'.

URL: $h$ ttps://doi.org/10.1594/PANGAEA.879227

Holmgren, W. F., Hansen, C. W. and Mikofski, M. A. (2018), 'pvlib python: a python package for modeling solar energy systems', J. Open Source Softw. $3(29), 884$.

Inanlouganji, A., Reddy, T. A. and Katipamula, S. (2018), 'Evaluation of regression and neural network models for solar forecasting over different short-term horizons', Sci. Technol. Built Environ. 24(9), 1004-1013.

Ineichen, P. (2008), 'A broadband simplified version of the Solis clear sky model', Sol. Energy 82, 758-762.

Ineichen, P. (2016), 'Validation of models that estimate the clear sky global and beam solar irradiance', Sol. Energy 132, 332-344. 
Ineichen, P. and Perez, R. (2002), 'A new airmass independent formulation for the Linke turbidity coefficient', Sol. Energy 73, 151-157.

Jager, D. and Andreas, A. (1996), 'NREL National Wind Technology Center (NWTC): M2 Tower; Boulder, Colorado (Data)'.

URL: $h t t p: / / d x . d o i . o r g / 10.5439 / 1052222$

Kallis, A. (2019), 'Basic and other measurements of radiation at station Toravere (2019-08)'.

URL: https://doi.pangaea.de/10.1594/PANGAEA.905738

Kasten, F. and Czeplak, G. (1980), 'Solar and terrestrial radiation dependent on the amount and type of cloud', Sol. Energy 24(2), 177-189.

Kazmi, H., Mehmood, F., Lodeweyckx, S. and Driesen, J. (2018), 'Gigawatthour scale savings on a budget of zero: Deep reinforcement learning based optimal control of hot water systems', Energy 144, 159-168.

King, D. L., Boyson, W. E., Hansen, B. R. and Bower, W. I. (1998), Improved accuracy for low-cost solar irradiance sensors, in '2nd World Conf. Exhib. Photovolt. Sol. Energy Convers.', Vienna, Austria, pp. 1-4.

King, D. L. and Myers, D. R. (1997), Silicon-Photodiode Pyranqmeters : Operational Characteristics ,, in 'Conf. Rec. 26th IEEE Photovolt. Spec. Conf.', Anaheim (CA), US, pp. 1285-1288.

Knap, W. (2019), 'Basic and other measurements of radiation at station Cabauw (2019-07)'.

URL: https://doi.pangaea.de/10.1594/PANGAEA.904864

Larson, V. E. (2013), Forecasting solar irradiance with numerical weather prediction models, in J. Kleissl, ed., 'Sol. Energy Forecast. Resour. Assess.', Academic Press, chapter 12, pp. 299-318.

Lefèvre, M., Oumbe, A., Blanc, P., Espinar, B., Gschwind, B., Qu, Z., Wald, L., Schroedter-Homscheidt, M., Hoyer-Klick, C., Arola, A., Benedetti, A., Kaiser, J. W. and Morcrette, J. J. (2013), 'McClear: A new model estimating downwelling solar radiation at ground level in clear-sky conditions', Atmos. Meas. Tech. 6(9), 2403-2418.

López Lorente, J., Liu, X., Morrow, D. J. and Brogan, P. V. (2019), Potential for crowdsourced weather stations to assess intra-hourly variability of photovoltaic systems, in '36th Eur. Photovolt. Sol. Energy Conf. Exhib. (EUPVSEC)', Marseille, France, pp. 1410-1416.

Madhavan, B. L., Kalisch, J. and Macke, A. (2016), 'Shortwave surface radiation network for observing small-scale cloud inhomogeneity fields', Atmos. Meas. Tech. 9(3), 1153-1166.

Muneer, T. and Gul, M. S. (2000), 'Evaluation of sunshine and cloud cover based models for generating solar radiation data', Energy Conversion and Management 41(5), 461-482.

Olano, X. (2019), 'Basic measurements of radiation at station Cener (2019-02)'. URL: https://doi.pangaea.de/10.1594/PANGAEA.899067 
Olefs, M. (2019), 'Basic measurements of radiation at station Sonnblick (201908)'.

URL: https://doi.pangaea.de/10.1594/PANGAEA.905736

Olson, K. and Andreas, A. (2012), 'Natural Energy Laboratory of Hawaii Authority (NELHA): Hawaii Ocean Science \& Technology Park; Kailua-Kona, Hawaii (Data)'.

URL: $h t t p: / / d x$. doi.org/10.7799/1183461

Pham, A., Jin, T., Novoa, C. and Qin, J. (2019), 'A multi-site production and microgrid planning model for net-zero energy operations', Int. J. Prod. Econ. 218, 260-274.

Reno, M. J. and Hansen, C. W. (2016), 'Identification of periods of clear sky irradiance in time series of GHI measurements', Renew. Energy 90, 520-531.

Rigollier, C., Bauer, O. and Wald, L. (2000), 'On the Clear Sky model of the ESRA - European Solar Radiation Atlas - with respect to the Heliosat method', Sol. Energy 68(1), 33-48.

Robledo, L. and Soler, A. (2000), 'Luminous efficacy of global solar radiation for clear skies', Energy Convers. Manag. 41, 1769-1779.

Sengupta, M., Gotseff, P., Myers, D. and Stoffel, T. (2012), Performance testing using silicon devices - Analysis of accuracy, in 'Conf. Rec. 32th IEEE Photovolt. Spec. Conf.', IEEE, pp. 3290-3293.

Sengupta, M., Habte, A., Gueymard, C. A., Wilbert, S., Renné, D. and Stoffel, T. (2017), Best Practices Handbook for the Collection and Use of Solar Resource Data for Solar Energy Applications: Second Edition, Technical Report December 2017, U.S. Department of Energy, Golden (CO), U.S.

URL: https://www.nrel.gov/docs/fy18osti/68886.pdf

The Weather Company (IBM) (2019), 'The Weather Underground - Wundermap'.

URL: www.wunderground.com/wundermap

Touzani, S., Granderson, J. and Fernandes, S. (2018), 'Gradient boosting machine for modeling the energy consumption of commercial buildings', Energy Build. 158, 1533-1543.

Urraca, R., Antonanzas, J., Sanz-Garcia, A., Aldama, A. and Martinez-de Pison, F. J. (2018), An algorithm based on satellite observations to quality control ground solar sensors: Analysis of Spanish meteorological networks, in '13th Int. Conf. Hybrid Artif. Intell. Syst.', Springer International Publishing, Oviedo, Spain, pp. 609-621.

Vignola, F., Chiu, C.-Y., Peterson, J., Dooraghi, M. and Sengupta, M. (2017), Comparison and analysis of instruments measuring plane of array irradiance for one-axis tracking PV systems, in '2017 IEEE 44th Photovolt. Spec. Conf. PVSC 2017', pp. 1169-1174. 
Vignola, F., Peterson, J., Kessler, R., Dooraghi, M., Sengupta, M. and Mavromatakis, F. (2018), Evaluation of Photodiode-based Pyranometers and Reference Solar Cells on a Two-Axis Tracking System, in '2018 IEEE 7th World Conf. Photovolt. Energy Conversion, WCPEC 2018 - A Jt. Conf. 45th IEEE PVSC, 28th PVSEC 34th EU PVSEC', pp. 2376-2381.

Walter-Shea, E. A., Hubbard, K. G., Mesarch, M. A. and Roebke, G. (2019), 'Improving the calibration of silicon photodiode pyranometers', Meteorol. Atmos. Phys. 131(4), 1111-1120.

Wilbert, S., Geuder, N., Schwandt, M., Kraas, B., Jessen, W., Meyer, R. and Nouri, B. (2015), Best Practives for Solar Irradiance Measurements with Rotating Shadowband Irradiometers: A report of IEA SHC Task 46, Solar Resource Assessment and Forecasting, Technical report, International Energy Agency.

URL: $\quad$ www.iea-shc.org/Data/Sites/1/publications/INSRSI_IEATask46B1_BestPractices-RSI_150819.pdf

Wilbert, S., Kleindiek, S., Nouri, B., Geuder, N., Habte, A., Schwandt, M. and Vignola, F. (2016), Uncertainty of rotating shadowband irradiometers and Si-pyranometers including the spectral irradiance error, in 'AIP Conf. Proc.', Vol. 1734, AIP Publishing, pp. 1-11. 